\section{Leak jeopardizes shuttle launch}

\section{Washington}

A LEAK in an oxidizer fuel-tank on the space shuttle Discovery threatens to delay the planned September resumption of shuttle flights by as much as two months.

Engineers and technicians at the National Aeronautics and Space Administration (NASA) Kennedy Space Center have postponed until after a test firing of the shuttle's main engines on 28 July the decision whether to attempt to repair the leak on the launch pad or to return Discovery to the Orbiter Processing Facility.

NASA engineers have localized the leak to a seal on a vent line above the oxidizer tank for the reaction control system, a set of thrusters used to control the spacecraft's position in orbit. But the seal cannot easily be reached, in its location inside the left-hand pod housing the manoeuvring system at the base of the orbiter, so that it is unclear whether it can be repaired on the launch pad. NASA transferred Discovery to the launch pad on 4 July.

Finding the leak forced a two-day delay in preparations for this week's firing of the main shuttle engine, intended to prove its readiness for flight. That 20 -second test is one of last crucial steps needed to declare the space shuttle orbit-worthy. Another hurdle that must be cleared is a final test firing of the newly designed solid rocket booster now scheduled for next month.

If Discovery must be returned to its hangar, there will be at least a two-month delay before the flight can be rescheduled.

Joseph Palca

\section{Progress at CERN}

\section{London}

FinANCIAL problems aside, things are going well at CERN, the European laboratory for particle physics. Two weeks ago, a beam of four positron bunches was successfully injected into the new Large ElectronPositron Collider (LEP) and transferred into the first $2.5 \mathrm{~km}$ of the tunnel. In what was the last major milestone before LEP is switched on next year, the whole injection system was found to work perfectly.

When completed, LEP will be the world's most powerful electron-positron colliding beam machine and will give particle physicists wordwide the facilities for performing experiments at energies of 200 $\mathrm{GeV}$. LEP consists of a water-cooled, leadshielded vacuum tube surrounded by magnets. Electrons travelling clockwise and positrons circulating anticlockwise will be kept on track by the magnets inside this same vacuum chamber. Construction began on LEP in 1983 and the total cost is around $£ \mathbf{4 0 0}$ million. Christine McGourty

\title{
Caltech seeks to improve its seismic monitoring
}

Berkeley

WHEN the magnitude 5.9 Whittier Narrows earthquake jolted Los Angeles last October, seismometers near the site went off the scale, requiring California Institute of Technology seismologists to rely on readings from stations hundreds of miles away. Within a few years, Caltech seismologists hope to be able to monitor earthquakes as large as magnitude 7 from nearby stations, thanks to a new southern California seismic network, called Terrascope, for "terrestrial telescope".

Over the past five years, Caltech seismologists have realized that their current seismic array of more than 250 conventional analog or digital seismometers is "woefully obsolete", says Don L. Anderson, director of Caltech's seismological laboratory. Data from the seismometers, some of which have been

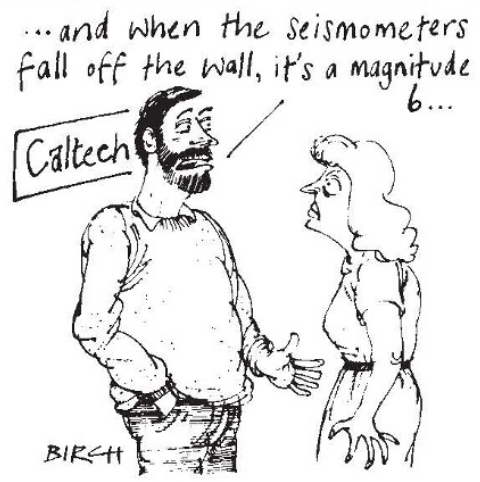

in operation for 60 years, can take months or years to analyse. The process is slowed by tedious analog-to-digital data conversion, and complicated by the limited dynamic range of conventional seismometers, which allow magnitude 1 or 2 earthquakes to slip by undetected, while those of magnitude 5 or greater send the instruments off scale.

The Terrascope will allow seismologists for the first time to make continuous observations of the complete process of earthquakes, including minor foreshocks and aftershocks, and the slow creep that occurs between earthquakes. When completed, the Terrascope will consist of a $\$ 4.2$ million array of at least 10 seismometers with a dynamic range 10,000 times greater than that of conventional instruments, allowing detection of a broad range of earthquake intensities. They can also detect a much greater range of frequencies of vibration than conventional seismometers.

With the help of continuous digital recording and fast computers, the array will provide data in real time, even during the earthquake. A computer database will allow comparisons with earthquakes in the area over the past 60 years.
The Terrascope stations will also be linked to the Global Positioning Satellite network, which will provide position data precise enough to allow tracking of the slow (several centimetres per year) movement of the tectonic plates that occurs between earthquakes.

A prototype station, a collaborative effort between Caltech, the University of Southern California, Harvard University and the US Geological Survey, has been operating for six months in the Pasadena hills. It has remained on scale through nearby magnitude-5 earthquakes, said Anderson, and based on its performance Caltech is ready to build the array.

The Terrascope's seismic stations will use 'off-the-shelf' equipment, said Anderson, including a Swiss sensor and a data logger developed by a Harvard graduate student. Anderson said the whole array could be completed within three years, once funding is secured. Marcia Barinaga

\section{Thin films carry}

\section{more current}

\section{Tokyo}

IN an important step on the way to practical applications of high-temperature superconductors, researchers at Sumitomo Electric Industries in Japan have made a polycrystalline thin film of bismuth-strontium-calcium copper oxide with unusually high current-carrying capacity

The bismuth-based superconductor, developed in Japan earlier this year, has been the object of intensive study, whereas in the United States the equally new thallium-based materials are the main attraction. But until now the currentcarrying capacity of bismuth superconductor has reached no more than about 100,000 amps per $\mathrm{cm}^{2}$ in thin films, too low for electronic applications.

Sumitomo researchers say they have increased the current-carrying capacity by an order of magnitude to 1.9 million amps per $\mathrm{cm}^{2}$ at liquid-nitrogen temperature by producing a polycrystalline film in which the crystals are aligned so that the copper-oxide planes, along which current flows most easily, are parallel to the film.

Comparable critical currents have previously been reported only for single crystals of rare earth superconductors (for example, see Nature 328,$98 ; 1987)$. Polycrystalline films, potentially more useful in electronics because they are not limited by crystal size, usually show much lower critical currents because of the effects of crystal boundaries. David Swinbanks 